\title{
REVIEWS
}

\section{Current and emerging therapeutic targets for IBD}

\section{Markus F. Neurath}

Abstract | Various therapeutic advances have led to a paradigm shift in the clinical management of patients with IBD. The introduction of immunosuppressive (such as azathioprine) and biologic agents (such as TNF blockers) has markedly reduced the need to use corticosteroids for therapy. Furthermore, the $\alpha 4 \beta 7$ integrin blocker vedolizumab has been introduced for clinical IBD therapy. Moreover, various new inhibitors of cytokines (for example, IL-6-IL-6R and IL-12-IL-23 blockers or apremilast), modulators of cytokine signalling events (for example, JAK inhibitors or SMAD7 blocker), inhibitors of transcription factors (for example, GATA3 or ROR $\gamma \mathrm{t}$ ) and new anti-adhesion and anti-T-cell-activation and migration strategies (for example, $\beta 7$ integrin, sphingosine 1 -phosphate receptors and MAdCAM1 inhibitors, regulatory T-cell therapy and stem cells) are currently being evaluated in controlled clinical trials. This Review aims to provide a comprehensive overview about current and future therapeutic approaches for IBD therapy. Furthermore, potential mechanisms of action of these therapeutic approaches and their implications for clinical therapy in IBD are discussed.

Inflammatory bowel diseases (including IBD, exemplified by Crohn's disease and ulcerative colitis) are chronic relapsing disorders affecting the gastrointestinal tract. IBD has a progressive and destructive nature and, therefore, can cause various complications including stenoses, abscesses, fistulas, extraintestinal manifestations and colitis-associated neoplasias and cancer $^{1,2}$. Thus, effective therapeutic approaches are of high clinical relevance in patients with IBD. This Review summarizes current therapeutic strategies and highlights emerging new treatment approaches for IBD with special reference to the proposed molecular mechanisms of action of anti-inflammatory drugs.

\section{Current IBD therapies}

Classic anti-inflammatory drugs. 5-Aminosalicylates (5-ASAs) are important anti-inflammatory drugs that are frequently used for anti-inflammatory therapy in patients with ulcerative colitis ${ }^{3}$. By contrast, 5-ASAbased drugs show little or no efficacy in inducing resolution of clinical symptoms and tissue inflammation in patients with Crohn's disease ${ }^{4}$.

5-ASAs are effective for induction and maintenance of remission in ulcerative colitis and might also reduce the risk of developing colitis-associated tumours in these patients ${ }^{5}$. Several mechanisms of action for 5-ASAs have been proposed, including reduction of prostaglandin synthesis via inhibition of cyclooxygenase, suppression of proinflammatory cytokine production and oxygen-free radicals, inhibition of lipoxygenase, blockade of neutrophil chemotaxis and mast cell activation, and impairment of nuclear factor- $\kappa \mathrm{B}$ activation $(\mathrm{NF}-\kappa \mathrm{B})$ in immune cells ${ }^{3}$. Moreover, studies in mice revealed that 5-ASA-based drugs augment peroxisome proliferator-activated receptor- $\gamma$ (PPAR $\gamma)$ expression and promote PPAR $\gamma$ translocation from the cytoplasm to the nucleus where they result in activation of peroxisome-proliferator hormone response element-driven genes to suppress colitis activity ${ }^{6,7}$.

In addition to 5-ASAs, corticosteroids (systemically or topically delivered) have been used for remission induction in ulcerative colitis ${ }^{2}$. Although corticosteroids favour induction of remission in both ulcerative colitis and Crohn's disease, they are not suitable for maintenance of remission in $\mathrm{IBD}^{1,2}$. Mechanistically, glucocorticoids bind to a specific cytosolic receptor followed by translocation of the complex to the nucleus to either activate or repress gene transcription (via binding to DNA corticosteroid-response elements) $)^{8,9}$. Additionally, the glucocorticoid-receptor complex can inactivate proinflammatory transcription factors such as NF- $\kappa \mathrm{B}$ and activator protein 1 (AP1) via proteinprotein interactions, thereby preventing their activation of inflammatory mediators (for example, leukotrienes and cytokines such as IL-1 and IL-6). 


\section{Key points}

- Several new drugs have been introduced into clinical IBD therapy in the past few decades that have helped to reduce corticosteroid use (e.g. anti-TNF and anti-integrin agents)

- A large unmet need for novel therapeutic approaches exists, as many patients do not respond to the clinically approved drugs, including TNF blockers and vedolizumab

- Many new therapeutic approaches have been developed based on studies in IBD mouse models, analyses of IBD tissues and new insights into inflammatory pathways in other chronic inflammatory disorders

- Cytokine blockers (such as ustekinumab and JAK inhibitors) suppressing cytokine signalling are probably a new addition to our future clinical armamentarium for patients with IBD

- New therapeutic concepts might enable achievement of new strict end points in IBD therapy, including mucosal healing, deep remission, transmural healing and histological healing

- Identification of biomarkers to predict and monitor therapeutic success will be crucial to enable individualized therapy in both Crohn's disease and ulcerative colitis as well as for treatment of fistulas in Crohn's disease, highlighting the broad relevance of anti-TNF therapy ${ }^{14,24}$. In 2015 and 2016, infliximab biosimilars - biological products that are highly similar in structure and clinical efficacy to an already FDA-approved biological reference product - were approved for clinical therapy and adalimumab biosimilars are currently under development ${ }^{34}$.

Anti-TNF agents such as infliximab can be combined with immunosuppressive agents such as azathioprine in IBD. In fact, prospective clinical trials ${ }^{14,35}$ showed that combination therapy with infliximab and azathioprine is superior to induce corticosteroid-free clinical remission than monotherapy with either agent in both Crohn's disease and ulcerative colitis. Further studies indicated that initiation of more intensive treatment early in the course of the disease could result in improved outcomes ${ }^{36,37}$. Specifically, early combined immunosuppression (so-called top-down therapy with early azathioprine plus infliximab followed by de-escalation if possible) reduced the risk of major adverse outcomes in Crohn's disease as compared with conventional management (so-called step-up therapy: first corticosteroids, followed, in sequence, by azathioprine and then infliximab). Although early combined immunosuppression was not associated with an increased risk of serious drug-related adverse events or mortality in several studies ${ }^{34,37}$, future studies will have to determine the risk of adverse events of long-term combined immunosuppressive therapy. The described combination therapy with immunosuppressive agents and TNF antagonists is probably the best strategy for achieving optimal outcomes in patients at high risk of disease progression (for example, fistulizing or extensive disease). However, long-term prospective studies are still needed to understand the value of early combination therapy to prevent bowel damage, loss of gastrointestinal tract function and permanent disability ${ }^{38}$.

TNF is produced by various immune and nonimmune cells in the inflamed gut of patients with IBD, including macrophages, $T$ cells, dendritic cells, fibroblasts and fat cells ${ }^{39}$. This cytokine has pleiotropic effects in the bowel wall: it induces neoangiogenesis ${ }^{40}$; activates macrophages to produce proinflammatory cytokines; favours Paneth cell death via necroptosis ${ }^{41}$; augments apoptosis of intestinal epithelial cells ${ }^{42}$; regulates T-cell apoptosis ${ }^{40,43,44}$; and reduces production of tissue inhibitor of matrix metalloproteinases (MMPs) by fibroblasts to mediate tissue injury via activated MMPs ${ }^{45}$. Thus, anti-TNF antibodies can suppress intestinal inflammation in IBD through several mechanisms.

However, the anti-TNF agent etanercept has shown no efficacy in patients with Crohn's disease ${ }^{46}$, suggesting differences among anti-TNF drugs. Several potential explanations for this observation have been suggested. First, differences in tissue degradation of anti-TNF antibodies were found. After MMP3 and MMP12 induced proteolytic degradation, cleaved infliximab and adalimumab functioned as F(ab')2 fragments, whereas cleaved etanercept lost its ability to neutralize $\mathrm{TNF}^{47}$. This finding suggests that rapid MMP-induced 
degradation of etanercept might limit its capacity to block TNF in the inflamed mucosa in IBD. Second, only full IgG1 monoclonal anti-TNF antibodies such as infliximab and adalimumab were found to induce regulatory macrophages with wound-healing potential via Fc receptor signalling, suggesting that etanercept might fail to regulate macrophage function in $\mathrm{IBD}^{48}$. Third, in comparison to other TNF blockers, etanercept has a lower affinity to transmembrane $\mathrm{TNF}^{49}$. Membrane-bound TNF, however, is an important co-stimulatory signal for TNFR2 on mucosal T cells in IBD and mediates their resistance to apoptosis ${ }^{43}$. Thus, other TNF blockers might more effectively induce T-cell apoptosis than etanercept and such apoptosis induction has been shown to correlate with clinical responses to anti-TNF therapy in vivo ${ }^{44}$. Consistently, the presence of membranebound TNF on mucosal immune cells in vivo has been identified as a predictor of response to subsequent antiTNF therapy ${ }^{50}$, further highlighting the relevance of membrane-bound TNF in IBD pathogenesis.

\section{Current and emerging drugs}

T-cell trafficking: integrin blockers and beyond. Studies over the past 10 years have found that $\sim 30-50 \%$ of patients with IBD do not respond to anti-TNF therapy, indicative of the need for new therapies. Experimental studies indicated that blockade of activated lymphocyte homing to the inflamed gut might provide a new approach for therapy of intestinal inflammation ${ }^{51,52}$. Subsequently, the anti- $\alpha 4$ integrin antibody natalizumab was tested in clinical trials for Crohn's disease therapy to block T-cell homing to the inflamed intestine via $\alpha 4 \beta 7$ integrins ${ }^{53-55}$ (FIG. 1). However, in spite of evidence for

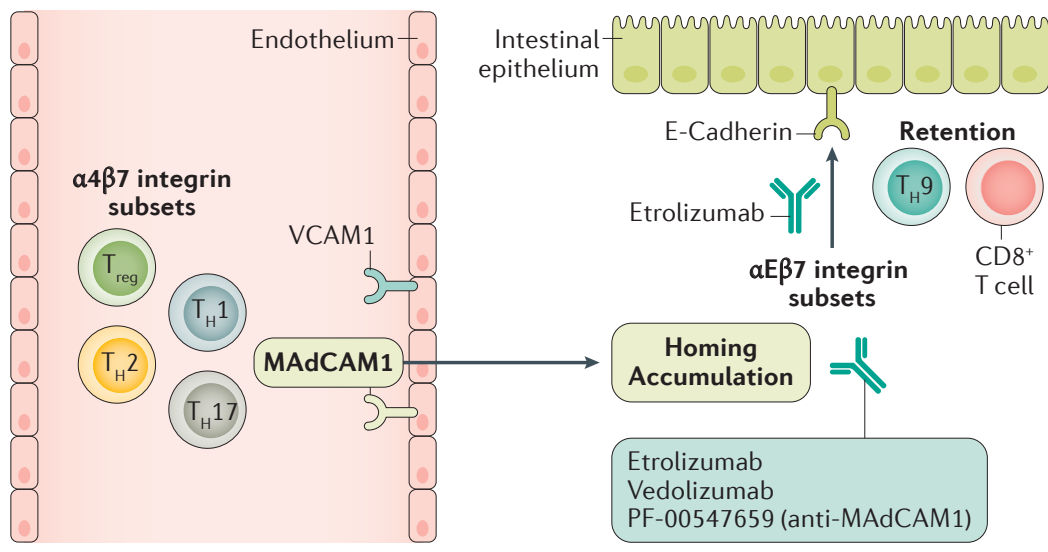

Figure $1 \mid$ New therapeutic approaches in IBD therapy based on blockade of T-cell homing and retention. Several new drugs - vedolizumab, anti-MAdCAM1 antibodies and etrolizumab - target T-cell homing and retention as a therapeutic target in IBD. Specifically, inhibition of the interaction between $\alpha 4 \beta 7$ integrins on T cells with MAdCAM1 on gut endothelial cells (via vedolizumab or etrolizumab) blocks homing of $T_{H} 1, T_{H} 2, T_{H} 17$ and $T_{\text {reg }}$ cells to the inflamed colon in IBD and their subsequent accumulation in the tissue. Moreover, targeting of the interaction between $\alpha \mathrm{E}$ on intestinal T cells with E-cadherin on gut epithelial cells (via etrolizumab) inhibits the retention of $\mathrm{T}_{\mathrm{H}} 9$ and $\mathrm{CD}^{+} \mathrm{T}$ cells in the inflamed tissue in IBD. Thus, targeting of both T-cell homing and retention affects T-cell trafficking and might be used to suppress local T-cell accumulation in gut inflammation. MAdCAM1, mucosal addressin cell adhesion molecular $1 ; T_{H} 1$, type 1 Thelper cell; $T_{H}$, type $2 T$ helper cell; $T_{H} 9$, type 9 Thelper cell; $\mathrm{T}_{\mathrm{H}} 17$, type 17 Thelper cell; $\mathrm{T}_{\text {reg }}$, regulatory $\mathrm{T}$ cell; $\mathrm{VCAM} 1$, vascular adhesion protein 1. clinical efficacy in Crohn's disease, treatment-related JC virus infections causing progressive multifocal leukoencephalopathy limited the use of this agent in IBD therapy ${ }^{56}$. For example, in JC virus-seropositive patients with prior immunosuppressant use, the incidence of progressive multifocal leukoencephalopathy during months 25-48 of natalizumab therapy was reported to be 19.5 per thousand; without prior immunosuppressant use, the incidence during months $25-48$ was $\sim 7.4$ per thousand ${ }^{57}$. These infections were probably related to natalizumab-induced blockade of T-cell homing to the brain via $\alpha 4 \beta 1$ integrins, suggesting that a more specific blockade of $\alpha 4 \beta 7$ integrins was important. Subsequently, the $a 4 \beta 7$-integrin-specific antibody vedolizumab was developed and showed efficacy in clinical phase III trials for remission induction and maintenance in Crohn's disease and ulcerative colitis ${ }^{58-63}$.

Although controlled clinical trials suggested that vedolizumab might induce more rapid clinical remission in ulcerative colitis than in Crohn's disease ${ }^{59,60}$, subsequent real-world data confirmed efficacy of this drug for moderate-severe Crohn's disease in routine clinical practice ${ }^{64}$ with similar rates of long-term remission in Crohn's disease and ulcerative colitis ${ }^{65}$. The reasons for potential differences between vedolizumab in Crohn's disease versus ulcerative colitis remain to be determined. Clinically, vedolizumab and TNF blockers are usually considered as alternative first-line induction treatment for patients with moderate-severe Crohn's disease and ulcerative colitis despite conventional therapy (with corticosteroids). Additionally, vedolizumab can be used in patients already exposed to anti-TNF agents. Prospective studies comparing vedolizumab with TNF blockers such as infliximab in anti-TNFagent-naive patients will determine the precise positioning of vedolizumab in the treatment algorithm for IBD. On the basis of the success of the anti- $\alpha 4 \beta 7$ integrin approach with vedolizumab, further therapies targeting T-cell homing are currently tested in clinical trials including anti-MAdCAM1 antibodies (PF-00547659) and the anti- $\beta 7$ integrin antibody etrolizumab ${ }^{66-68}$ (FIG. 1). The latter drug is particularly interesting, as it blocks not only a $4 \beta 7$-mediated homing but additionally T-cell retention via inhibition of $\alpha \mathrm{E}(\mathrm{CD} 103) \beta 7$-mediated binding to E-cadherin on gut epithelial cells ${ }^{66,67}$. Consistently, in a humanized mouse model of colitis with ulcerative colitis T cells, etrolizumab was superior to vedolizumab in reducing $\mathrm{T}$-cell trafficking in the inflamed tissue due to effects on ulcerative colitis T-cell retention ${ }^{66}$. However, phase III clinical data on clinical efficacy and safety of etrolizumab are still missing, although phase II data indicated efficacy for induction of remission in ulcerative colitis ${ }^{67}$.

Another important development in the context of immune cell trafficking in IBD relates to sphingosine 1-phosphate (S1P) signalling ${ }^{69}$. The bioactive lipid S1P has been shown to activate NF- $\kappa$ B and STAT3 transcription factors via a family of five $G$ protein-coupled receptors (S1PR) expressed on lymphocytes (so-called inside-out signalling). Functionally, S1PR signalling induces cell proliferation, vascular permeability and 
angiogenesis ${ }^{69}$. Moreover, S1PR expressed in immune cells controls their egress from lymph nodes to lymph and plasma and S1PR agonists cause lymphopenia in blood and thoracic duct lymph by cell sequestration in lymph nodes ${ }^{69}$. Inhibition of lymphocyte recirculation via S1PR signalling suppressed experimental colitis and development of colitis-associated neoplasias in mice ${ }^{70-72}$. Thus, S1P receptor agonists (ozanimod (formerly known as RPC1063), APD334 and MT-1303) have been tested in human ulcerative colitis. For instance, ozanimod is an oral agonist of S1PR subtypes 1 and 5 that induces peripheral lymphocyte sequestration. A phase II trial indicated that ozanimod (daily dose of $1 \mathrm{mg}$ ) results in a slightly higher clinical remission rate in ulcerative colitis than placebo, suggesting that such drugs might be therapeutically effective in human ulcerative coli$\mathrm{tis}^{73}$. However, further prospective studies are needed to determine efficacy and safety of ozanimod treatment in ulcerative colitis.

Emerging targets in fibrosis and tissue remodelling. Tissue remodelling and destruction in patients with IBD is controlled by MMPs. In this context, expression of MMP9 was found to be increased in IBD, particularly in patients with ulcerative colitis ${ }^{74}$. Functional data in experimental models of inflammation have suggested an important role of MMP9 in impairing colonic epithelial permeability and augmenting inflammation via activation of myosin light chain kinase $(\mathrm{MLCK})^{74}$. Furthermore, MMP9 favoured angiogenesis and created a proteolytic environment in the inflamed gut of a mouse model of colitis that stimulated the influx of myeloid cells into the colonic epithelium and the production of TNF ${ }^{75,76}$. Consecutively, a potent and highly selective allosteric MMP9 inhibitor (humanized monoclonal antibody GS-5745) has been developed and is currently being tested in clinical trials in patients with $\mathrm{IBD}^{76}$ (FIG. 2). However, in September 2016, the company has stopped its combined phase II/III clinical study of GS-5745 among patients with moderately to severely active ulcerative colitis due to insufficient evidence of a treatment benefit in the group of patients randomly assigned to receive either one of two doses of GS-5745 (REF. 77).

To ameliorate tissue fibrosis in IBD, enzymes controlling degradation of matrix compounds might be druggable targets. Specifically, a study has examined carbohydrate sulfotransferase 15 (CHST15) in gut inflammation $^{78}$. CHST15 is a specific enzyme biosynthesizing chondroitin sulfate $\mathrm{E}$ that binds to various pathogenic mediators and favours tissue fibrosis. In experimental acute dextran sulfate sodium colitis, small-interfering RNA (siRNA)-based silencing of CHST15 reduced colitis activity and intestinal accumulation of $\mathrm{F} 4 / 80^{+}$macrophages and ER-TR7 ${ }^{+}$fibroblasts. In chronic dextran sulfate sodium colitis, CHST15
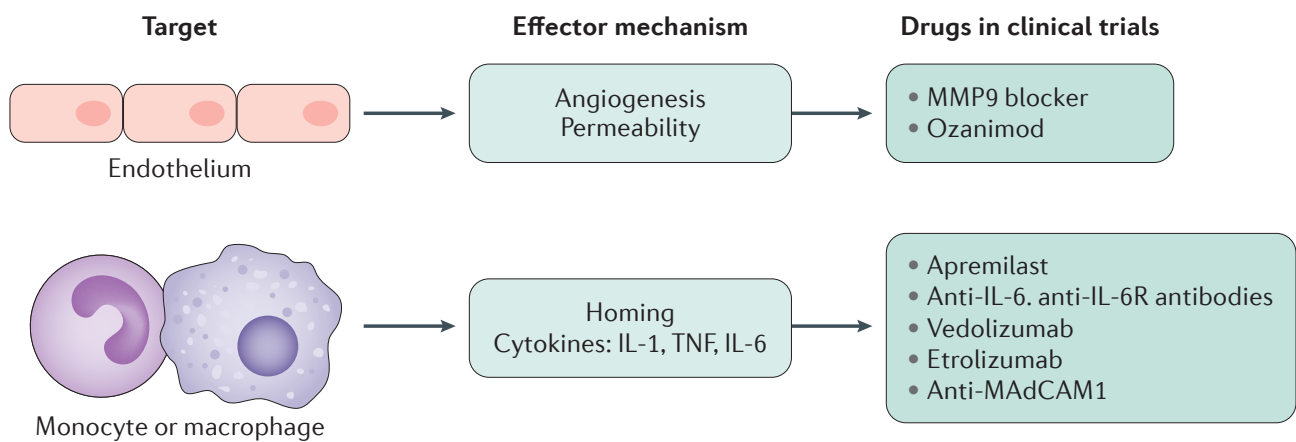

Monocyte or macr

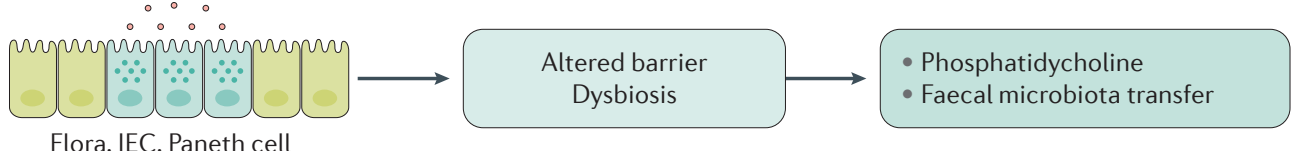

Flora, IEC, Paneth cell

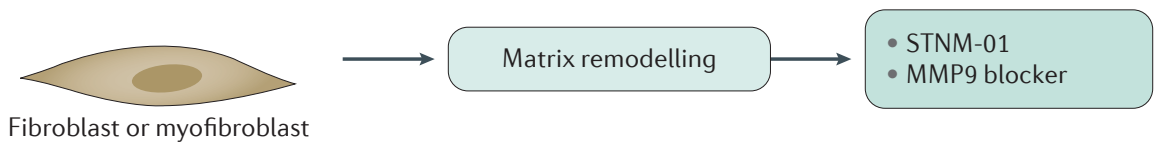

Fibroblast or myofibroblast

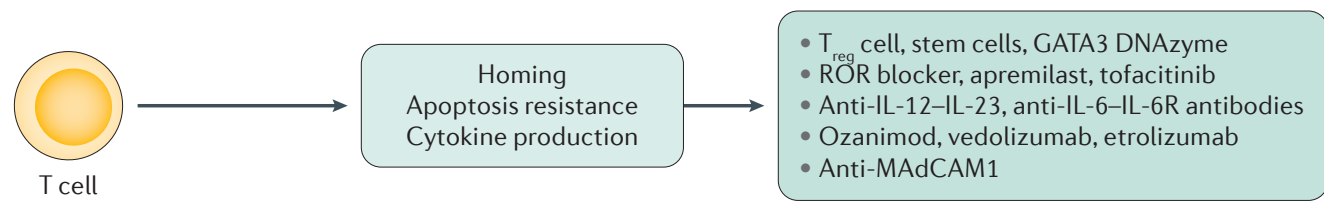

Figure 2 | New therapeutic approaches in IBD with their specific targets. Modulation of barrier function, gut microbiota, matrix remodelling, macrophage and lymphocyte activation, homing and retention, as well as angiogenesis, are emerging new targets for therapy. This schematic diagram shows the target, proposed mechanisms and agent in development. IEC, intestinal epithelial cell; IL-6R, IL-6 receptor; MAdCAM1, mucosal addressin cell adhesion molecular 1 ; MMP9, matrix metalloproteinase 9; ROR, RAR-related orphan receptor; $\mathrm{T}_{\text {reg }}$ cell, regulatory $\mathrm{T}$ cell. 


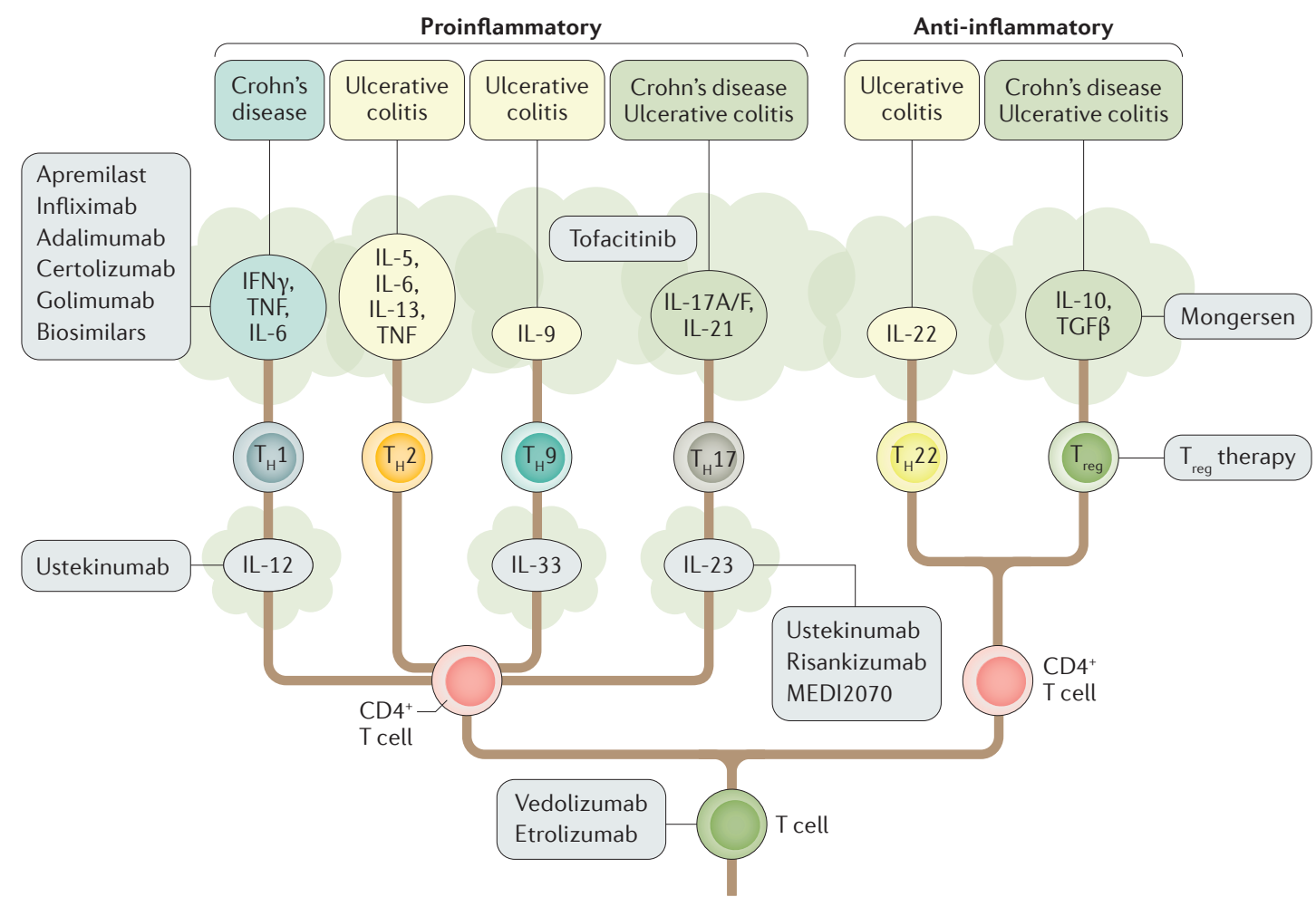

Figure 3 | The T-cell cytokine tree in IBD. Various T-cell subsets, their differentiation pathways and their signature cytokines have been identified in patients with IBD. Some of these cytokines, as well as T-cell homing and activation, are important new targets for therapeutic approaches in IBD. Although IL-12-induced mucosal $\mathrm{T}_{H} 1$ cells producing IFN $\gamma$, TNF and IL- 6 have been detected in Crohn's disease, $\mathrm{T}_{\mathrm{H}}$ 2-type cytokines such as IL-5 and IL-13 are induced in ulcerative colitis. Moreover, $\mathrm{T}_{\mathrm{H}} 17$ cells that are activated by IL-23 have been seen in both Crohn's disease and ulcerative colitis. Additionally, IL-33-induced $\mathrm{T}_{\mathrm{H}} 9$ cells have been identified in ulcerative colitis. Finally, a reduction of IL-22-producing T cells was detected in ulcerative colitis, as well as a reduced ratio between regulatory T cells (producing IL-10 and TGF $\beta$ ) and effector $T$ cells in the inflamed mucosa in IBD. The potential target structures of new therapeutic approaches in IBD are indicated. TGF, transforming growth factor; $T_{H} 1$, type 1 Thelper cell; $T_{H} 2$, type $2 T$ helper cell; $T_{H} 9$, type 9 T helper cell; $\mathrm{T}_{\mathrm{H}} 17$, type $17 \mathrm{~T}$ helper cell; $\mathrm{T}_{\mathrm{H}} 22$, type $22 \mathrm{~T}$ helper cell; $\mathrm{T}_{\text {reg }}$, regulatory $T$ cell.

siRNA reduced colitis activity and numbers of $a-S M A$ (smooth muscle actin)-positive fibroblasts and collagen deposition. Furthermore, a phase I study in 18 patients with Crohn's disease published in 2016 determined the safety of STNM01, a synthetic double-stranded RNA oligonucleotide directed against CHST15, in Crohn's disease $^{79}$. The majority of individuals who received STNM01 showed a reduction of endoscopic inflammation as compared with placebo therapy. Moreover, histological analyses revealed that STNM01 reduces tissue fibrosis in Crohn's disease. Larger prospective studies on this compound are needed to determine the efficacy of this new therapeutic approach.

New blockers of proinflammatory cytokines and cytokine signalling. On the basis of the success of antiTNF agents in IBD there has been an intensive search for additional effective anticytokine strategies. However, several studies on new cytokine blockers have yielded disappointing results. For instance, the anti-IFN $\gamma$ antibody fontolizumab showed low efficacy in patients for treatment of active Crohn's disease ${ }^{80}$. Moreover, the anti-IL-17A antibody secukinumab resulted in aggravation of Crohn's disease in many patients, possibly owing to the protective effects of IL-17A on gut epithelial cells ${ }^{81-83}$. Consistently, IL-17A inactivation did not result in amelioration of experimental colitis in mice $^{84,85}$. In addition to IFN $\gamma$ and IL-17A blockers, two prospective studies did not show efficacy of anti-IL-13 antibodies (anrukinzumab, tralokinumab) in patients with ulcerative colitis despite promising results in animal models of colitis ${ }^{86-89}$. In contrast to these observations, additional cytokine blockers have shown more promising results in clinical trials that will be reviewed in the next paragraphs (FIGS 3,4).

IL-6 is a proinflammatory cytokine activating immune cells ${ }^{90,91}$. In patients with IBD, levels of IL-6 and its agonistic soluble receptor (sIL-6R) are induced and mediate activation of $\mathrm{T}$ cells and their resistance against programmed cell death (apoptosis) ${ }^{92}$. In experimental colitis models, IL-6R blockade was effective in suppressing intestinal inflammation. Consistently, a small pilot study using an anti-IL-6R antibody (tocilizumab, previously known as MRA) suggested higher response and remission rates in Crohn's disease than the placebo group ${ }^{93}$. Additionally, according to results presented in abstract form, an IL-6 antibody (PF-04236921) yielded higher clinical response (Crohn's disease activity 


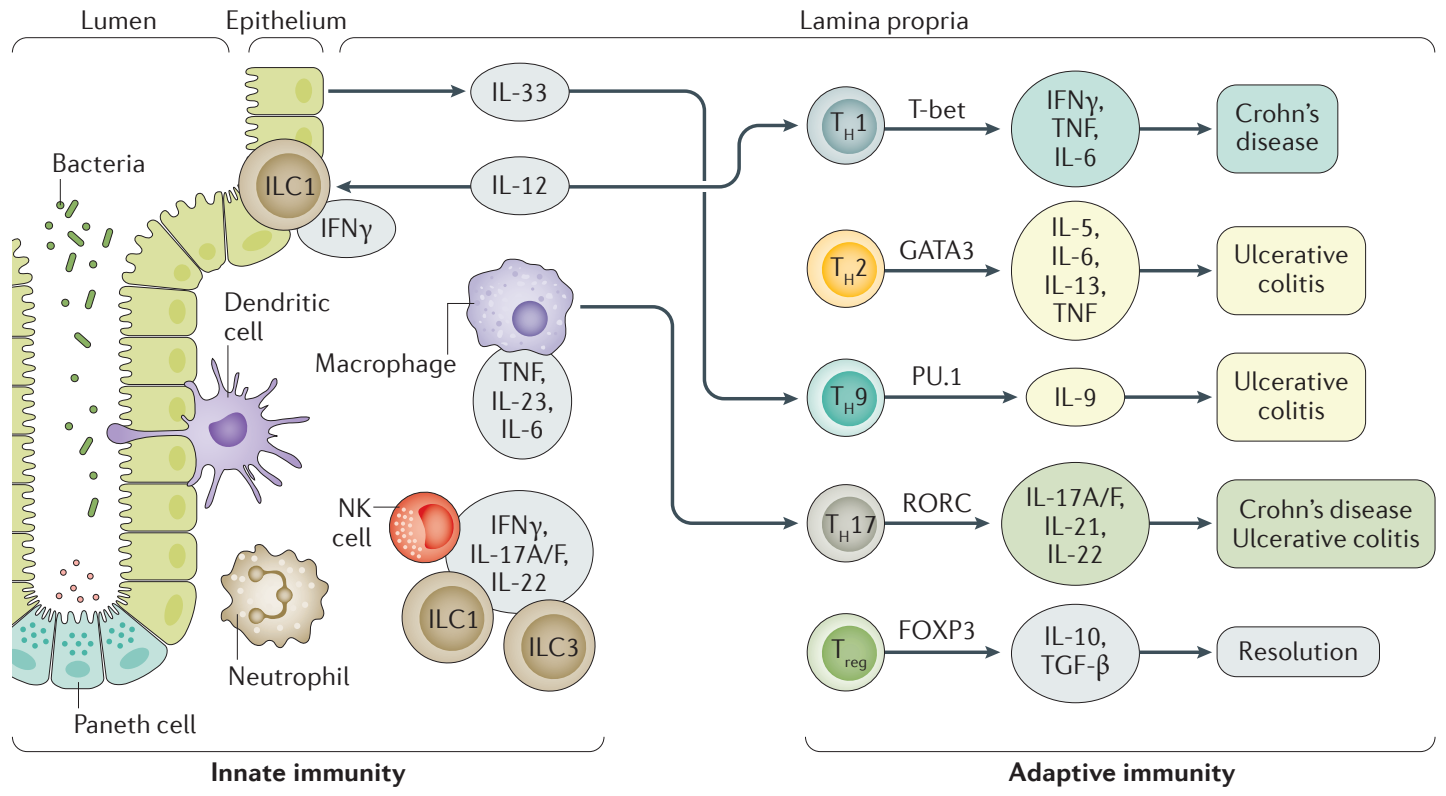

Figure 4 | Proinflammatory immune cells and their crosstalk in patients with IBD. Although IL-12-driven type 1 Thelper $\left(T_{H} 1\right)$ cells and IL-23-activated type 17 T helper $\left(T_{H} 17\right)$ cells were detected in Crohn's disease, type $2 T_{\text {helper }}\left(T_{H} 2\right)$, type $9 T$ helper $\left(T_{H} 9\right)$ and $T_{H} 17$ cells were identified in ulcerative colitis. The key transcription factors for each T-cell subset as well as the subset associated signature cytokines are indicated. NK cell, natural killer cell; $\mathrm{T}_{\text {reg }}$ cell, regulatory $\mathrm{T}$ cell.

index-70) and remission rates in patients with Crohn's disease than placebo therapy ${ }^{94}$. However, cases with abscess formation and perforations were noted upon start of therapy possibly owing to protective, proliferative effects of membrane-bound IL-6R signalling on gut epithelial cells. In future studies, gp130-Fc fusion proteins could elucidate the role of sIL-6R signalling in Crohn's disease, as such proteins specifically block signalling via the soluble but not the membrane-bound IL-6R.

IL-12 p35-p40 and IL-23 p19-p40 are two heterodimeric, proinflammatory cytokines that are induced in the inflamed mucosa of patients with Crohn's disease $^{95,96}$. Consistent with the type $1 \mathrm{~T}$ helper $\left(\mathrm{T}_{\mathrm{H}} 1\right)$ inducing potential of IL-12, Crohn's disease was found to be associated with mucosal $\mathrm{T}_{\mathrm{H}} 1$ responses. Moreover, type $17 \mathrm{~T}$ helper $\left(\mathrm{T}_{\mathrm{H}} 17\right)$ responses were noted in both patients with Crohn's disease and ulcerative colitis ${ }^{39,97}$, possibly owing to the presence of IL-23 as a well-known activator of $\mathrm{T}_{\mathrm{H}} 17 \mathrm{~T}$ cells. These data provided a rational basis for targeting of $\mathrm{T}_{\mathrm{H}} 1$ and $\mathrm{T}_{\mathrm{H}} 17$ cytokines in IBD (FIG. 2). Functional studies with genetically engineered animals and IL-23 p19 and p40 blockers suggested that blockade of these cytokine subunits might effectively suppress intestinal inflammation in mouse models of colitis ${ }^{98-104}$. In particular, IL-23 inhibition was effective and prevented activation of T cells and innate lymphoid cells and tissue destruction in vivo.

Subsequently, various antibodies against IL-12IL-23 p40 and IL-23 p19 subunits were developed for clinical trials (such as ABT-874, ustekinumab, risankizumab, LY-2525623, AMG139/MEDI2079 and guselkumab) ${ }^{105-107}$. Studies with ABT-874 and ustekinumab as p40 blockers demonstrated higher response rates in patients with Crohn's disease than placebo. Initial studies also revealed that ustekinumab was particularly effective for therapy in patients with Crohn's disease who had previously taken anti-TNF agents ${ }^{105,106}$. On the basis of successful phase III studies in both anti-TNF agent-naive and anti-TNF agent-experienced patients (UNITI-1 and UNITI-2 programmes), ustekinumab was recently approved for Crohn's disease therapy in the USA and in Europe $)^{108}$. Potentially, p19 blockers such as risankizumab will also be available for Crohn's disease therapy in the future, as the latest phase II data presented as a late breaker abstract suggested efficacy for this antibody in patients with active Crohn's disease ${ }^{109}$.

Cytokine signalling is mediated upon binding of cytokines to their specific receptors via intracellular activation of Janus kinases (JAKs: JAK1, JAK2, JAK3, TYK2). Thus, blockade of JAK kinases might be used to suppress cytokine signalling in mucosal immune cells. As individual JAKs mediate cell activation via several cytokines (for example, JAK3 is activated via IL-2, IL-4, IL-7, IL-9, IL-15 and IL-21) with proposed proinflammatory roles in colitis ${ }^{110-113}$, this approach opens the possibility to block the activity of several proinflammatory cytokines simultaneously. Indeed, several JAK inhibitors (tofacitinib, ABT494 and filgotinib) have been developed for clinical therapy ${ }^{114,115}$. Interestingly, the JAK1-JAK3 blocker tofacitinib, a suppressor of T-cell, natural-killer-cell and B-cell activation, yielded very promising results in a phase II study in patients with ulcerative colitis, but was not effective in patients with Crohn's disease ${ }^{114,115}$. Moreover, filgotinib, a selective JAK1 inhibitor, showed increased remission rates in patients with moderate to severe Crohn's disease $^{116}$. Although the efficacy and safety profiles of these drugs will have to be determined in large phase III trials, these findings indicate that JAK inhibitors hold promise for clinical therapy of patients with IBD. 
Finally, phosphodiesterase (PDE) 4 inhibitors are currently being tested in patients with IBD. PDE4 inhibitors such as apremilast and roflumilast regulate inflammatory processes by degrading cyclic adenosine 3'5'-monophosphate (cAMP), a key second messenger $^{117}$. Inhibition of PDE4 increases the intracellular cAMP level, which in turn blocks proinflammatory mediators and favours production of anti-inflammatory proteins. In particular, apremilast has been found to impair the production of the proinflammatory cytokines IFN $\gamma$, TNF, IL-12, IL-17 and IL-23 (REF. 118), indicating that PDE4 blockers are multicytokine inhibitors with potential therapeutic effects in IBD.

Blockers of transcription factors controlling cytokine gene transcription. Transcription factors regulating cytokine gene expression are potential future drug targets in $\mathrm{IBD}^{119,120}$. Theoretically, targeting such regulatory proteins might enable suppression of the production of several proinflammatory cytokines at the same time. Potential strategies for targeting include siRNA, DNAzymes and chemical inhibitors. A study published in 2016 used a chemical inhibitor of ROR $\gamma \mathrm{t}$, a master transcription factor in $\mathrm{T}_{\mathrm{H}} 17$ cells, for successful therapy of experimental T-cell-dependent colitis in mice ${ }^{120}$. Furthermore, genetic ROR $\gamma$ deficiency of T cells prevented T-cell transfer of colitis in RAG-knockout mice ${ }^{84}$. As RORA and RORC proteins, as well as $\mathrm{T}_{\mathrm{H}} 17$ cytokines, are augmented in patients with $\mathrm{IBD}^{121,122}$, these data suggested that targeting of ROR proteins might be useful in these patients. Moreover, both genetic and pharmacological (via DNAzyme) blockade of GATA3, a key transcription factor for $\mathrm{T}_{\mathrm{H}} 2$ cytokine gene transcription, ameliorated chronic oxazolone-mediated and TNBS (2,4,6-trinitrobenzenesulfonic acid)-mediated colitis in mice ${ }^{119}$. As GATA3 expression is induced in patients with active ulcerative colitis and correlates with $\mathrm{T}_{\mathrm{H}} 2$ and $\mathrm{T}_{\mathrm{H}} 9$ cytokine levels in this disease, these observations indicate that GATA3 might be targeted for therapy of ulcerative colitis in humans. Indeed, GATA3 DNAzyme therapy has been successfully tested in patients with asthma ${ }^{123}$, a chronic inflammatory disorder of the airways associated with type $2 \mathrm{~T}$ helper $\left(\mathrm{T}_{\mathrm{H}} 2\right)$ cytokine production.

Strengthening barrier function and activation of anti-inflammatory pathways. Escherichia coli Nissle $(\mathrm{EcN})$ is a nonpathogenic Gram-negative strain that controls intestinal barrier function and induces antiinflammatory proteins ${ }^{124,125}$. EcN is an established clinical therapy for patients with ulcerative colitis and exhibits similar anti-inflammatory effects compared with $5-\mathrm{ASAs}^{125}$. EcN has direct antimicrobial effects, controls biofilm formation, stimulates human $\beta$-defensin production by intestinal epithelial cells, and strengthens tight junctions by upregulating zonula occludens proteins ${ }^{125}$. In addition to this probiotic strain, several other probiotic approaches as well as faecal transplantation have been considered for IBD therapy, although unequivocal results have been obtained ${ }^{126,127}$. However, a randomized controlled trial in adults with active ulcerative colitis demonstrated that faecal microbiota transplantation ( $50 \mathrm{ml}$, via enema from healthy anonymous donors) once weekly for 6 weeks induced markedly higher remission rates than placebo ${ }^{126}$. Further studies are required to determine the efficacy and safety of this approach in larger patient cohorts and over longer time periods.

Additional therapeutic approaches for IBD have been designed that might regulate barrier function and anti-inflammatory pathways. Defects in mucin production are well-known in patients with ulcerative colitis ${ }^{128}$, and so phosphatidylcholine (lecithin) therapy has been tested in patients with promising results in phase II studies $^{129}$. The results of the phase III study in patients with ulcerative colitis are expected in 2017. Moreover, IL-22 therapy or modulation of IL-22-binding protein have been tested successfully in mouse colitis models and proposed as new approaches for IBD therapy ${ }^{130}$. The IL-22 cytokine directly activates proliferation of intestinal epithelial cells via STAT3 activation and induces production of protective barrier proteins such as REG proteins ${ }^{131}$. Moreover, modulators of Toll-like receptor (TLR) signalling have been considered for IBD therapy ${ }^{132}$. CpG-site-containing oligonucleotides suppress immune cell activation and protect barrier function in experimental colitis via TLR9 signalling ${ }^{133}$. Finally, the TLR7 ligand imiquimod suppressed CD11 $\mathrm{c}^{+}$dendritic cells and activated intestinal epithelial cells to produce antimicrobial peptides, resulting in reduced colitis activity ${ }^{134}$.

The ratio between effector $\mathrm{T}$ cells and regulatory $\mathrm{T}\left(\mathrm{T}_{\text {reg }}\right)$ cells is markedly increased in patients with $\mathrm{IBD}^{135}$. Thus, it is tempting to speculate that increasing $\mathrm{T}_{\text {reg }}$-cell numbers via $\mathrm{T}_{\text {reg }}$-cell transfer might restore the balance between proinflammatory and anti-inflammatory immune cells as a new therapeutic approach in IBD. Indeed, naturally occurring $\mathrm{T}_{\text {reg }}$ cells, TGF $\beta$-induced $\mathrm{T}_{\text {reg }}$ cells as well as ex vivo expanded $\mathrm{T}_{\text {reg }}$ cells have been used for therapy of experimental colitis in mice and led to suppressed colitis activity induced by effector T cells ${ }^{136,137}$. In patients with IBD, a 12-week, singleinjection, escalating-dose, phase I/IIa clinical pilot study in refractory Crohn's disease with ovalbuminspecific $\mathrm{T}_{\text {reg }}$ cells was well tolerated and had dose-related efficacy ${ }^{138}$ (FIG. 3). On the basis of these results, various clinical studies are currently studying the effects of $\mathrm{T}_{\text {reg }}$-cell based immune therapy in IBD.

Finally, activation of TGF $\beta$ signalling in immune cells via inhibition of SMAD7 has been tested in a phase II study in patients with Crohn's disease ${ }^{139,140}$. This study was based on previous findings showing that blockade of SMAD7 expression in experimental colitis augmented TGF $\beta$ signalling via SMAD3 and caused suppression of colitis activity. The clinical phase II trial with an antisense SMAD7 blocker, denoted mongersen, showed markedly higher rates of remission and clinical response in mongersen-treated patients than the placebo-treated group. Owing to these promising results of the phase II programme, a phase III study will determine the efficacy and safety of mongersen in a larger group of patients with Crohn's disease. 
Stem cells for Crohn's disease fistulas. Crohn's disease is associated with the development of complex fistulas that are challenging to treat ${ }^{141,142}$. Adipose-derived allogeneic stem cells have been considered as new treatment approaches for such fistulas ${ }^{12,143}$. Experimental studies revealed that mesenchymal stem cells (MSCs) might exert potent immunomodulatory effects on antigenspecific T cells in Crohn's disease through paracrine and cell-cell contact-mediated actions ${ }^{14}$. Clinically, local administration of allogeneic, expanded MSCs in initial trials was not associated with severe adverse events in patients with Crohn's disease who had perianal fistulas and seemed to promote healing. A large randomized trial subsequently showed that allogeneic MSCs (120 million Cx601 cells) induced remission (closure of external openings of fistulas and absence of collections $>2 \mathrm{~cm}$ ) more frequently than placebo ${ }^{145}$. Furthermore, a phase I-IIa study suggested potential beneficial effects of MSCs in rectovaginal fistulas in Crohn's disease, suggesting that MSCs might be broadly applicable for fistula therapy in patients with Crohn's disease ${ }^{146}$.

\section{Conclusions}

Several new drugs such as anti-TNF agents and vedolizumab have been introduced into clinical IBD therapy in the past few decades that have helped to reduce corticosteroid use and to augment response and remission rates. Evidence in both Crohn's disease and ulcerative colitis has been obtained that indicate some of these drugs synergistically suppress immune cell activation and gut inflammation (for example, azathioprine plus infliximab), highlighting the potential of combination therapies ${ }^{14,35}$. However, there is still a large unmet need for novel therapeutic approaches as many patients do not respond to the clinically approved drugs, including TNF blockers and vedolizumab ${ }^{14,28,60}$. Thus, a plethora of new drugs are currently being tested in clinical trials in IBD that challenge established treatment regimens (FIG. 2). Many of these new therapeutic approaches have been developed on the basis of studies in IBD mouse models, genetic studies, analyses of IBD tissues and new insights into inflammatory pathways in other chronic inflammatory disorders, such as rheumatoid arthritis and psoriasis ${ }^{97,117,147,148}$. Some of these new agents might gain approval by FDA and the European Medicines Agency and might enable new strict end points in IBD therapy to be achieved ${ }^{149,150}$, including mucosal healing on endoscopy, deep remission (clinical remission plus mucosal healing), transmural healing and histological healing, thereby raising the bar for future drugs in IBD therapy and possibly preventing severe IBD-associated complications such as surgery and hospitalizations. In this context, new cytokine and signalling blockers have yielded promising results and will probably add to our future clinical armamentarium in patients with IBD ${ }^{106,115}$. With the introduction of additional approved drugs in the future, it will be of crucial importance to identify biomarkers to predict and monitor therapeutical success to enable individualized therapy in IBD.
1. Baumgart, D. C. \& Sandborn, W. J. Crohn's disease Lancet 380, 1590-1605 (2012).

2. Danese, S. \& Fiocchi, C. Ulcerative colitis. N. Engl. J. Med. 365, 1713-1725 (2011).

3. Allgayer, H. Review article: mechanisms of action of mesalazine in preventing colorectal carcinoma in inflammatory bowel disease. Aliment. Pharmacol. Ther. 18 (Suppl. 2), 10-14 (2003).

4. Lim, W. C., Wang, Y., MacDonald, J. K. \& Hanauer, S. Aminosalicylates for induction of remission or response in Crohn's disease. Cochrane Database Syst. Rev. 7, CD008870 (2016).

5. Velayos, F. S., Terdiman, J. P. \& Walsh, J. M. Effect of 5-aminosalicylate use on colorectal cancer and dysplasia risk: a systematic review and metaanalysis of observational studies. Am. Gastroenterol. 100, 1345-1353 (2005).

6. Desreumaux, P. \& Romano, O. 5-Aminosalicylates and colorectal cancer: preventive role in chronic inflammatory bowel disease? Gastroenterol. Clin. Biol. 28, 509 (in French) (2004).

7. Rousseaux, C. et al. Intestinal antiinflammatory effect of 5-aminosalicylic acid is dependent on peroxisome proliferator-activated receptor-gamma. J. Exp. Med. 201, 1205-1215 (2005).

8. Oakley, R. H. \& Cidlowski, J. A. The biology of the glucocorticoid receptor: new signaling mechanisms in health and disease. J. Allergy Clin. Immunol. 132 1033-1044 (2013).

9. Rezaie, A et al. Budesonide for induction of remission in Crohn's disease. Cochrane Database Syst. Rev. 6 , CD000296 (2015)

10. Tiede, I. et al. CD28-dependent Rac1 activation is the molecular target of azathioprine in primary human CD4 + T lymphocytes. J. Clin. Invest. 111 1133-1145 (2003)

11. Atreya, I. et al. Designer thiopurine-analogues for optimised immunosuppression in inflammatory bowel diseases. J. Crohns Colitis 10, 1132-1143 (2016).

12. Oancea, I. et al. Colonic microbiota can promote rapid local improvement of murine colitis by thioguanine independently of T lymphocytes and host metabolism. Gut 66, 59-69 (2016)

13. D'Haens, G., Geboes, K., Ponette, E., Penninckx, F. $\&$ Rutgeerts, P. Healing of severe recurrent ileitis with azathioprine therapy in patients with Crohn's disease. Gastroenterology 112, 1475-1481 (1997).

14. Colombel, J. F. et al. Infliximab, azathioprine, or combination therapy for Crohn's disease. N. Engl. J. Med. 362, 1383-1395 (2010).

15. Feagan, B. G. et al. A comparison of methotrexate with placebo for the maintenance of remission in Crohn's disease. North American Crohn's Study Group Investigators. N. Engl. J. Med. 342, 1627-1632 (2000).

16. Feuerstein, J. D., Akbari, M., Tapper, E. B. $\&$ Cheifetz, A. S. Systematic review and metaanalysis of third-line salvage therapy with infliximab or cyclosporine in severe ulcerative colitis. Ann. Gastroenterol. 29, 341-347 (2016).

17. Feagan, B. G. et al. Methotrexate for the treatment of Crohn's disease. The North American Crohn's Study Group Investigators. N. Engl. J. Med. 332, 292-297 (1995)

18. Steiner, S. et al. Cyclosporine a regulates proinflammatory cytokine production in ulcerative colitis. Arch Immunol Ther Exp. (Warsz) 63, 53-63 (2015).

19. Matsuda, S. \& Koyasu, S. Mechanisms of action of cyclosporine. Immunopharmacology 47, 119-125 (2000).

20. Nielsen, C. H., Albertsen, L., Bendtzen, K $\&$ Baslund, B. Methotrexate induces poly(ADP-ribose) polymerase-dependent, caspase 3-independent apoptosis in subsets of proliferating CD4 + T cells. Clin. Exp. Immunol. 148, 288-295 (2007).

21. Wessels, J. A., Huizinga, T. W. \& Guchelaar, H. J. Recent insights in the pharmacological actions of methotrexate in the treatment of rheumatoid arthritis. Rheumatology (Oxford) 47, 249-255 (2008).

22. Marinkovic, G., Hamers, A. A., de Vries, C. J. $\&$ de Waard, V. 6-Mercaptopurine reduces macrophage activation and gut epithelium proliferation through inhibition of GTPase Rac1. Inflamm. Bowel Dis. 20, 1487-1495 (2014).

23. Colombel, J. F. et al. Early mucosal healing with infliximab is associated with improved long-term clinical outcomes in ulcerative colitis. Gastroenterology 141, 1194-1201 (2011).

24. Hanauer, S. B. et al. Maintenance infliximab for Crohn's disease: the ACCENT I randomised trial. Lancet 359, 1541-1549 (2002).

25. Rutgeerts, P., Vermeire, S. \& Van Assche, G. Predicting the response to infliximab from trough serum levels. Gut 59, 7-8 (2010).

26. Schnitzler, F. et al. Mucosal healing predicts long-term outcome of maintenance therapy with infliximab in Crohn's disease. Inflamm. Bowel Dis. 15, 1295-1301 (2009).

27. Van den Brande, J. M. et al. Infliximab but not etanercept induces apoptosis in lamina propria T-lymphocytes from patients with Crohn's disease. Gastroenterology 124, 1774-1785 (2003).

28. Colombel, J. F. et al. Adalimumab induces deep remission in patients with Crohn's disease. Clin. Gastroenterol. Hepatol. 12, 414-422.e5 (2013)

29. Colombel, J. F. et al. Adalimumab for maintenance of clinical response and remission in patients with Crohn's disease: the CHARM trial. Gastroenterology 132, 52-65 (2007).

30. Sandborn, W. J. et al. Adalimumab induces and maintains clinical remission in patients with moderate-to-severe ulcerative colitis. Gastroenterology 142, 257-265.e3 (2012)

31. Sandborn, W. J. et al. Subcutaneous golimumab induces clinical response and remission in patients with moderate-to-severe ulcerative colitis. Gastroenterology 146, 85-95 (2013).

32. Sandborn, W. J. et al. Subcutaneous golimumab maintains clinical response in patients with moderateto-severe ulcerative colitis. Gastroenterology 146 96-109 (2013).

33. Deeks, E. D. Certolizumab pegol: a review in inflammatory autoimmune diseases. BioDrugs 30 , 607-617 (2016) 
34. Blair, H. A. \& Deeks, E. D. Infliximab biosimilar (CT-P13; infliximab-dyyb): a review in autoimmune inflammatory diseases. BioDrugs 30, 469-480 (2016).

35. Panaccione, R. et al. Combination therapy with infliximab and azathioprine is superior to monotherapy with either agent in ulcerative colitis. Gastroenterology 146, 392-400.e3 (2014).

36. D'Haens, G. et al. Early combined immunosuppression or conventional management in patients with newly diagnosed Crohn's disease: an open randomised trial. Lancet 371, 660-667 (2008).

37. Khanna, R. et al. Early combined immunosuppression for the management of Crohn's disease (REACT): a cluster randomised controlled trial. Lancet 386, 1825-1834 (2015)

38. Ordas, I., Feagan, B. G. \& Sandborn, W. J. Early use of immunosuppressives or TNF antagonists for the treatment of Crohn's disease: time for a change. Gut 60, 1754-1763 (2011)

39. Neurath, M. F. Cytokines in inflammatory bowel disease. Nat. Rev. Immunol. 14, 329-342 (2014).

40. Rutella, S. et al. Infliximab therapy inhibits inflammation-induced angiogenesis in the mucosa of patients with Crohn's disease. Am. J. Gastroenterol. 106, 762-770 (2011).

41. Gunther, C. et al. Caspase-8 regulates TNF-alphainduced epithelial necroptosis and terminal ileitis. Nature 477, 335-339 (2011).

42. Juuti-Uusitalo, K. et al. Differential effects of TNF (TNFSF2) and IFN-gamma on intestinal epithelial cell morphogenesis and barrier function in threedimensional culture. PLOS ONE 6, e22967 (2011).

43. Atreya, R. et al. Antibodies against tumor necrosis factor (TNF) induce T-cell apoptosis in patients with inflammatory bowel diseases via TNF receptor 2 and intestinal $\mathrm{CD} 14^{+}$macrophages. Gastroenterology 141, 2026-2038 (2011)

44. Van den Brande, J. M. et al. Prediction of antitumour necrosis factor clinical efficacy by real-time visualisation of apoptosis in patients with Crohn's disease. Gut 56, 509-517 (2007).

45. Meijer, M. J. et al. Effect of the anti-tumor necrosis factor-alpha antibody infliximab on the ex vivo mucosal matrix metalloproteinase-proteolytic phenotype in inflammatory bowel disease. Inflamm. Bowel Dis. 13, 200-210 (2007).

46. Sandborn, W. J. et al. Etanercept for active Crohn's disease: a randomized, double-blind, placebocontrolled trial. Gastroenterology 121, 1088-1094 (2001).

47. Biancheri, P. et al. Proteolytic cleavage and loss of function of biologic agents that neutralize tumor necrosis factor in the mucosa of patients with inflammatory bowel disease. Gastroenterology 149 , 1564-1574.e3 (2015)

48. Vos, A. C. et al. Anti-tumor necrosis factor-alpha antibodies induce regulatory macrophages in an Fc region-dependent manner. Gastroenterology 140 221-230 (2011)

49. Scallon, B. et al. Binding and functional comparisons of two types of tumor necrosis factor antagonists. J. Pharmacol. Exp. Ther. 301, 418-426 (2002).

50. Atreya, R. et al. In vivo molecular imaging using fluorescent anti-TNF antibodies predicts response to biological therapy in Crohn's disease. Nat. Med. 52, 313-318 (2014)

51. Podolsky, D. K. et al. Attenuation of colitis in the cotton-top tamarin by anti-alpha 4 integrin monoclonal antibody. J. Clin. Invest. 92, 372-380 (1993).

52. Picarella, D. et al. Monoclonal antibodies specific for beta 7 integrin and mucosal addressin cell adhesion molecule-1 (MAdCAM-1) reduce inflammation in the colon of scid mice reconstituted with CD45RBhigh CD4 + T cells. J. Immunol. 158, 2099-2106 (1997).

53. Ghosh, S. et al. Natalizumab for active Crohn's disease. N. Engl. J. Med. 348, 24-32 (2003).

54. Sandborn, W. J. et al. Natalizumab induction and maintenance therapy for Crohn's disease. $N$. Engl. J. Med. 353, 1912-1925 (2005).

55. Targan, S. R. et al. Natalizumab for the treatment of active Crohn's disease: results of the ENCORE Trial. Gastroenterology 132, 1672-1683 (2007).

56. Van Assche, G. et al. Progressive multifocal leukoencephalopathy after natalizumab therapy for Crohn's disease. N. Engl. J. Med. 353, 362-368 (2005).

57. Borchardt, J. \& Berger, J. R. Re-evaluating the incidence of natalizumab-associated progressive multifocal leukoencephalopathy. Mult. Scler. Relat. Disord. 8, 145-150 (2016).
58. Fischer, A. et al. Differential effects of alpha4beta7 and GPR 15 on homing of effector and regulatory $T$ cells from patients with UC to the inflamed gut in vivo. Gut 65, 1642-1664 (2016).

59. Feagan, B. G. et al. Vedolizumab as induction and maintenance therapy for ulcerative colitis. N. Engl. J. Med. 369, 699-710 (2013).

60. Sandborn, W. J. et al. Vedolizumab as induction and maintenance therapy for Crohn's disease. N. Engl. J. Med. 369, 711-721 (2013).

61. Wyant, T. et al. Vedolizumab affects antibody responses to immunisation selectively in the gastrointestinal tract: randomised controlled trial results. Gut 64, 77-83 (2015).

62. Bickston, S. J. et al. Vedolizumab for induction and maintenance of remission in ulcerative colitis. Cochrane Database Syst. Rev. 8, CD007571 (2014).

63. Lam, M. C. \& Bressler, B. Vedolizumab for ulcerative colitis and Crohn's disease: results and implications of GEMINI studies. Immunotherapy 6, 963-971 (2014).

64. Dulai, P. S. et al. The real-world effectiveness and safety of vedolizumab for moderate-severe Crohn's disease: results from the US VICTORY Consortium. Am. J. Gastroenterol. 111, 1147-1155 (2016).

65. Stallmach, A. et al. Vedolizumab provides clinical benefit over 1 year in patients with active inflammatory bowel disease - a prospective multicenter observational study. Aliment. Pharmacol. Ther. 44, 1199-1212 (2016).

66. Zundler, S. et al. Blockade of alphaEbeta7 integrin suppresses accumulation of CD8 + and Th9 lymphocytes from patients with IBD in the inflamed gut in vivo. Gut http://dx.doi.org/10.1136/ gutjnl-2016-312439 (2016).

67. Vermeire, S. et al. Etrolizumab as induction therapy for ulcerative colitis: a randomised, controlled, phase 2 trial. Lancet 384, 309-318 (2014).

68. Rutgeerts, P. J. et al. A randomised phase I study of etrolizumab (rhuMAb beta7) in moderate to severe ulcerative colitis. Gut 62, 1122-1130 (2013).

69. Gonzalez-Cabrera, P. J., Brown, S., Studer, S. M \& Rosen, H. S1P signaling: new therapies and opportunities. F100OPrime Rep. 6, 109 (2014).

70. Snider, A. J. et al. A role for sphingosine kinase 1 in dextran sulfate sodium-induced colitis. FASEB J. 23, 143-152 (2009).

71. Deguchi, Y. et al. The S1P receptor modulator FTY720 prevents the development of experimental colitis in mice. Oncol. Rep. 16, 699-703 (2006).

72. Degagne, E. \& Saba, J. D. S1 pping fire: sphingosine-1-phosphate signaling as an emerging target in inflammatory bowel disease and colitisassociated cancer. Clin. Exp. Gastroenterol. 7 205-214 (2014).

73. Sandborn, W. J. et al. Ozanimod induction and maintenance treatment for ulcerative colitis. N. Engl. J. Med. 374, 1754-1762 (2016)

74. Nighot, P. et al. Matrix metalloproteinase 9-induced increase in intestinal epithelial tight junction permeability contributes to the severity of experimental DSS colitis. Am. J. Physiol. Gastrointest. Liver Physiol. 309, G988-G997 (2015).

75. Matusiewicz, M., Neubauer, K.

Mierzchala-Pasierb, M., Gamian, A.

\& Krzystek-Korpacka, M. Matrix metalloproteinase-9; its interplay with angiogenic factors in inflammatory bowel diseases. Dis. Markers 2014, 643645 (2014)

76. Marshall, D. C. et al. Selective allosteric inhibition of MMP9 is efficacious in preclinical models of ulcerative colitis and colorectal cancer. PLOS ONE 10, e0127063 (2015).

77. Gilead Sciences, Inc. Gilead terminates phase 2/3 study of GS-5745 in patients with ulcerative colitis. Gilead http://www gilead com/news/press-releases/ 2016/9/gilead-terminates-phase-23-studyof-gs5745-in-patients-with-ulcerative-colitis (2016).

78. Suzuki, K. et al. Pivotal role of carbohydrate sulfotransferase 15 in fibrosis and mucosal healing in mouse colitis. PLOS ONE 11, e0158967 (2016).

79. Suzuki, K. et al. Phase 1 clinical study of siRNA targeting carbohydrate sulphotransferase 15 in Crohn's disease patients with active mucosal lesions. J. Crohns Colitis http://dx.doi.org/10.1093/ecco-jcc/ jjw143 (2016)

80. Reinisch, W. et al. A dose escalating, placebo controlled, double blind, single dose and multidose, safety and tolerability study of fontolizumab, a humanised anti-interferon gamma antibody, in patients with moderate to severe Crohn's disease. Gut 55, 1138-1144 (2006).
81. Hueber, W. et al. Secukinumab, a human anti-IL-17A monoclonal antibody, for moderate to severe Crohn's disease: unexpected results of a randomised, doubleblind placebo-controlled trial. Gut 61, 1693-1700 (2012).

82. Lee, J. S. et al. Interleukin-23-independent IL-17 production regulates intestinal epithelial permeability. Immunity 43, 727-738 (2015).

83. Maxwell, J. R. et al. Differential roles for interleukin-23 and interleukin-17 in intestinal immunoregulation. Immunity 43, 739-750 (2015).

84. Leppkes, M. et al. RORgamma-expressing Th1 7 cells induce murine chronic intestinal inflammation via redundant effects of IL-17A and IL-17F. Gastroenterology 136, 257-267 (2009).

85. Awasthi, A. \& Kuchroo, V. K. IL-17A directly inhibits TH1 cells and thereby suppresses development of intestinal inflammation. Nat. Immunol. 10, 568-570 (2009).

86. Heller, F. et al. Interleukin-13 is the key effector Th2 cytokine in ulcerative colitis that affects epithelial tight junctions, apoptosis, and cell restitution. Gastroenterology 129, 550-564 (2005).

87. Heller, F., Fuss, I. J., Nieuwenhuis, E. E., Blumberg, R. S. \& Strober, W. Oxazolone colitis, a Th2 colitis model resembling ulcerative colitis, is mediated by IL-13-producing NK-T cells. Immunity 17, 629-638 (2002)

88. Reinisch, W. et al. Anrukinzumab, an anti-interleukin 13 monoclonal antibody, in active UC: efficacy and safety from a phase lla randomised multicentre study. Gut 64, 894-900 (2015).

89. Danese, S. et al. Tralokinumab for moderateto-severe UC: a randomised, double-blind, placebo controlled, phase Ila study. Gut 64 243-249 (2015)

90. Yamamoto, M., Yoshizaki, K., Kishimoto, T. $\&$ Ito, H. IL-6 is required for the development of Th1 cell-mediated murine colitis. J. Immunol. 164 , 4878-4882 (2000).

91. Jones, S. A., Scheller, J. \& Rose-John, S. Therapeutic strategies for the clinical blockade of IL-6/gp 130 signaling. J. Clin. Invest. 121, 3375-3383 (2011).

92. Atreya, R. et al. Blockade of interleukin 6 trans signaling suppresses T-cell resistance against apoptosis in chronic intestinal inflammation: evidence in Crohn disease and experimental colitis in vivo. Nat. Med. 6, 583-588 (2000)

93. Ito, H. et al. A pilot randomized trial of a human antiinterleukin- 6 receptor monoclonal antibody in active Crohn's disease. Gastroenterology 126, 989-996 (2004).

94. Danese, S. et al. Results of ANDANTE, a randomised clinical study with an anti-IL6 antibody (PF-04236921) in subjects with Crohn's disease who are anti-tumor necrosis factor inadequate responders [abstract OP015]. J Crohns Colitis 10 (Suppl.1), S12-S13 (2016).

95. Fuss, I. J. et al. Both IL-12p70 and IL-23 are synthesized during active Crohn's disease and are down-regulated by treatment with anti-IL-12 p40 monoclonal antibody. Inflamm. Bowel Dis. 12, 9-15 (2006).

96. Monteleone, G. et al. Interleukin 12 is expressed and actively released by Crohn's disease intestinal lamina propria mononuclear cells. Gastroenterology 112 , 1169-1178 (1997)

97. Monteleone, I., Pallone, F. \& Monteleone, G. Th17-related cytokines: new players in the control of chronic intestinal inflammation. BMC Med. 9, 122 (2011).

98. Neurath, M. F. IL-23: a master regulator in Crohn disease. Nat. Med. 13, 26-28 (2007)

99. Neurath, M. F., Fuss, I., Kelsall, B. L., Stuber, E. \& Strober, W. Antibodies to interleukin 12 abrogate established experimental colitis in mice. J. Exp. Med. 182, 1281-1290 (1995)

100. De Nitto, D., Sarra, M., Cupi, M. L., Pallone, F. \& Monteleone, G. Targeting IL-23 and Th17-cytokines in inflammatory bowel diseases. Curr. Pharm. Des. 16 3656-3660 (2010)

101. Eken, A., Singh, A. K., Treuting, P. M. \& Oukka, M. $\mathrm{IL}-23 \mathrm{R}^{+}$innate lymphoid cells induce colitis via interleukin-22-dependent mechanism. Mucosal Immunol. 7, 143-154 (2014).

102. Geremia, A. et al. IL-23-responsive innate lymphoid cells are increased in inflammatory bowel disease. J. Exp. Med. 208, 1127-1133 (2011).

103. Uhlig, H. H. et al. Differential activity of IL-12 and IL-23 in mucosal and systemic innate immune pathology. Immunity 25, 309-318 (2006). 
104. Yen, D. et al. IL-23 is essential for T cell-mediated colitis and promotes inflammation via IL-17 and IL-6. J. Clin. Invest. 116, 1310-1316 (2006)

105. Sandborn, W. J. et al. A randomized trial of Ustekinumab, a human interleukin-12/23 monoclonal antibody, in patients with moderateto-severe Crohn's disease. Gastroenterology 135 1130-1141 (2008)

106. Sandborn, W. J. et al. Ustekinumab induction and maintenance therapy in refractory Crohn's disease. N. Engl. J. Med. 367, 1519-1528 (2012).

107. Mannon, P. J. et al. Anti-interleukin-12 antibody for active Crohn's disease. N. Engl. J. Med. 351, 2069-2079 (2004).

108. Feagan, B. G. et al. Ustekinumab as induction and maintenance therapy for Crohn's disease. N. Engl. J. Med. 375, 1946-1960 (2016).

109. Feagan, B. et al. Efficacy and safety of re-induction treatment with the selective IL-23 inhibitor risankizumab in patients with moderate to severe Crohn`s disease [abstract LB01]. United Eur. Gastroenterol. J. 4, 800-811 (2016).

110. Boland, B. S., Sandborn, W. J. \& Chang, J. T. Update on Janus kinase antagonists in inflammatory bowel disease. Gastroenterol. Clin. North Am. 43, 603-617 (2014).

111. Gerlach, K. et al. TH9 cells that express the transcription factor PU. 1 drive T cell-mediated colitis via IL-9 receptor signaling in intestinal epithelial cells. Nat. Immunol. 15, 676-686 (2014).

112. Monteleone, G. et al. Interleukin-21 enhances T-helpe cell type I signaling and interferon-gamma production in Crohn's disease. Gastroenterology 128, 687-694 (2005).

113. Shinohara, T. et al. Upregulated IL-7 receptor alpha expression on colitogenic memory CD4 + T cells may participate in the development and persistence of chronic colitis. J. Immunol. 186, 2623-2632 (2011).

114. Sandborn, W. J. et al. A phase 2 study of tofacitinib, an oral Janus kinase inhibitor, in patients with Crohn's disease. Clin. Gastroenterol. Hepatol. 12 1485-1493.e2 (2014)

115. Sandborn, W. J. et al. Tofacitinib, an oral Janus kinase inhibitor, in active ulcerative colitis. N. Engl. J. Med. 367, 616-624 (2012).

116. Vermeire, S. et al. Filgotinib, a selective JAK 1 inhibitor, induces clinical remission in patients with moderateto-severe Crohn's disease: interim analysis from the Phase 2 FITZROY study [abstract OP0200]. European Crohn's and Colitis Organisation [online], https:// www.ecco-ibd.eu/index.php/publications/congressabstract-s/abstracts-2016/item/op020-filgotiniba-selective-jak1-inhibitor-induces-clinical-remissionin-patients-with-moderate-to-severe-crohnix2019isdisease-interim-analysis-from-the-phase-2-fitzroyx 00a0study.html?highlight $=$ YToxOntpOjA7czox MDoiZmlsZ290aW5pYil7fO (2016).

117. Gooderham, M. \& Papp, K. Selective phosphodiesterase inhibitors for psoriasis: focus on apremilast. BioDrugs 29, 327-339 (2015).

118. Mazur, M., Karczewski, J., Lodyga, M., Zaba, R. \& Adamski, Z. Inhibitors of phosphodiesterase 4 (PDE 4): a new therapeutic option in the treatment of psoriasis vulgaris and psoriatic arthritis. J. Dermatolog. Treat. 26, 326-328 (2015).
119. Popp, V. et al. Rectal delivery of a DNAzyme that specifically blocks the transcription factor GATA3 reduces colitis in mice. Gastroenterology 152 176-192.e5 (2016).

120. Withers, D. R. et al. Transient inhibition of RORgammat therapeutically limits intestinal inflammation by reducing TH 17 cells and preserving group 3 innate lymphoid cells. Nat. Med. 22, 319-323 (2016)

121. Monteleone, I., Sarra, M., Pallone, F. \& Monteleone, C. Th17-related cytokines in inflammatory bowel diseases: friends or foes? Curr. Mol. Med. 12 592-597 (2012)

122. Kobayashi, T. et al. IL23 differentially regulates the Th1/Th17 balance in ulcerative colitis and Crohn's disease. Gut 57, 1682-1689 (2008).

123. Krug, N. et al. Allergen-induced asthmatic responses modified by a GATA3-specific DNAzyme. N. Engl. J. Med. 372, 1987-1995 (2015)

124. Lasaro, M. A. et al. F1C fimbriae play an important role in biofilm formation and intestinal colonization by the Escherichia coli commensal strain Nissle 1917. Appl. Environ. Microbiol. 75, 246-251 (2009).

125. Scaldaferri, F. et al. Role and mechanisms of action of Escherichia coli Nissle 1917 in the maintenance of remission in ulcerative colitis patients: an update. World J. Gastroenterol. 22, 5505-5511 (2016)

126. Moayyedi, P. et al. Fecal microbiota transplantation induces remission in patients with active ulcerative colitis in a randomized controlled trial. Gastroenterology 149, 102-109.e6 (2015).

127. Rossen, N. G. et al. Findings from a randomized controlled trial of fecal transplantation for patients with ulcerative colitis. Gastroenterology 149 , 110-118.e4 (2015)

128. Dorofeyev, A. E., Vasilenko, I. V., Rassokhina, O. A \& Kondratiuk, R. B. Mucosal barrier in ulcerative colitis and Crohn's disease. Gastroenterol. Res. Pract. 2013, 431231 (2013).

129. Stremmel, W., Hanemann, A., Ehehalt, R., Karner, M. \& Braun, A. Phosphatidylcholine (lecithin) and the mucus layer: evidence of therapeutic efficacy in ulcerative colitis? Dig. Dis. 28, 490-496 (2010)

130. Pelczar, P. et al. A pathogenic role for $\mathrm{T}$ cell-derived IL-22BP in inflammatory bowel disease. Science 354 358-362 (2016)

131. Pickert, G. et al. STAT3 links IL-22 signaling in intestinal epithelial cells to mucosal wound healing. J. Exp. Med. 206, 1465-1472 (2009).

132. Atreya, R. et al. Clinical effects of a topically applied Toll-like receptor 9 agonist in active moderateto-severe ulcerative colitis. J. Crohns Colitis 10, 1294-1302 (2016)

133. Rachmilewitz, D. et al. Toll-like receptor 9 signaling mediates the anti-inflammatory effects of probiotics in murine experimental colitis. Gastroenterology 126 , 520-528 (2004)

134. Sainathan, S. K. et al. Toll-like receptor-7 ligand Imiquimod induces type I interferon and antimicrobial peptides to ameliorate dextran sodium sulfate-induced acute colitis. Inflamm. Bowel Dis. 18, 955-967 (2012).

135. Maul, J. et al. Peripheral and intestinal regulatory CD4 + CD25 $5^{\text {high }} \mathrm{T}$ cells in inflammatory bowel disease. Gastroenterology 128, 1868-1878 (2005).
136. Powrie, F., Carlino, J., Leach, M. W., Mauze, S. $\&$ Coffman, R. L. A critical role for transforming growth factor-beta but not interleukin 4 in the suppression of T helper type 1-mediated colitis by CD45RB low CD4 + T cells. J. Exp. Med. 183, 2669-2674 (1996)

137. Fantini, M. C. et al. Transforming growth factor beta induced FoxP3 + regulatory T cells suppress Th1 mediated experimental colitis. Gut 55, 671-680 (2006).

138. Desreumaux, P. et al. Safety and efficacy of antigenspecific regulatory T-cell therapy for patients with refractory Crohn's disease. Gastroenterology 143 , 1207-1217.e2 (2012)

139. Monteleone, G., Boirivant, M., Pallone, F. \& MacDonald, T. T. TGF-beta1 and Smad7 in the regulation of IBD. Mucosal Immunol. 1 (Suppl. 1), S50-S53 (2008).

140. Monteleone, G. et al. Mongersen, an oral SMAD7 antisense oligonucleotide, and Crohn's disease. N. Engl. J. Med. 372, 1104-1113 (2015).

141. Present, D. H. Review article: the efficacy of infliximab in Crohn's disease - healing of fistulae. Aliment. Pharmacol. Ther. 13 (Suppl. 4), 23-28 (1999).

142. Molendijk, I. et al. Allogeneic bone marrow-derived mesenchymal stromal cells promote healing of refractory perianal fistulas in patients with Crohn's disease. Gastroenterology 149, 918-927.e6 (2015).

143. Herreros, M. D. et al. Autologous expanded adiposederived stem cells for the treatment of complex cryptoglandular perianal fistulas: a phase III randomized clinical trial (FATT 1: fistula Advanced Therapy Trial 1) and long-term evaluation. Dis. Colon Rectum 55, 762-772 (2012).

144. Ciccocioppo, R. et al. Ex vivo immunosuppressive effects of mesenchymal stem cells on Crohn's disease mucosal T. cells are largely dependent on indoleamine 2,3-dioxygenase activity and cell-cell contact. Stem Cell Res. Ther. 6, 137 (2015).

145. Panes, J. et al. Expanded allogeneic adipose-derived mesenchymal stem cells (Cx601) for complex perianal fistulas in Crohn's disease: a phase 3 randomised, double-blind controlled trial. Lancet 388, 1281-1290 (2016).

146. Garcia-Arranz, M. et al. Treatment of Crohn's-related rectovaginal fistula with allogeneic expanded-adipose derived stem cells: a phase I-Ila clinical trial. Stem Cells Transl Med. 5, 1441-1446 (2016).

147. Schett, G., Elewaut, D., McInnes, I. B., Dayer, J. M. $\&$ Neurath, M. F. How cytokine networks fuel inflammation: toward a cytokine-based disease taxonomy. Nat. Med. 19, 822-824 (2013).

148. Danese, S. New therapies for inflammatory bowel disease: from the bench to the bedside. Gut 61 918-932 (2012).

149. Neurath, M. F. \& Travis, S. P. Mucosal healing in inflammatory bowel diseases: a systematic review. Gut 61, 1619-1635 (2012).

150. Bryant, R. V. et al. Beyond endoscopic mucosal healing in UC: histological remission better predicts corticosteroid use and hospitalisation over 6 years of follow-up. Gut 65, 408-414 (2016).

\section{Competing interests statement}

M.F.N. has served as an adviser for Abbvie, Boehringer, Genentech, Giuliani/PPM, Janssen, MSD, Pentax and Takeda. 
ERRATUM

Current and emerging therapeutic targets for IBD

Markus Neurath

Nature Reviews Gastroenterology \& Hepatology 14, 269-278 (2017)

In the version of this Review published online and in print, representation of the target for the drugs ustekinumab,

risankizumab and MEDI2070 were not accurate in Figure 3 and should have highlighted that ustekinumab targets IL-12 and IL-23, whereas MEDI2070 and risankizumab both act on IL-23. The error has been corrected for the HTML and PDF versions of the article. 